\title{
Variational Calculus (Optimal Control) Applied to the Optimization of the Enzymatic Synthesis of Ampicillin
}

\author{
Marcelo Perencin de Arruda Ribeiro* and Roberto de Campos Giordano \\ Departamento de Engenharia Química; Universidade Federal de São Carlos; C.P. 676; 13565-905; São Carlos - \\ SP - Brasil
}

\begin{abstract}
In this work, optimal control techniques were used to optimize the feed of reactants during the enzymatic synthesis of ampicillin in a semi-batch reactor. Simulation results showed that a semi-batch integrated reactor (with product crystallization) might achieve 88\% 6-APA (6-aminepenicillanic acid) conversion and 92\% of PGME (phenylglycine methyl ester) yield, with a productivity between 3.5 and $5.5 \mathrm{mM} \mathrm{min}^{-1}$.
\end{abstract}

Key words: Synthesis of $\beta$-lactam antibiotics, fed-batch reactor optimization, optimal control

\section{INTRODUCTION}

Ampicillin is one of the most clinically important $\beta$-lactam antibiotics. Nowadays, its industrial production route is the chemical synthesis. It is a complex route in which organic chlorite compounds and extreme temperatures $\left(\approx-30^{\circ} \mathrm{C}\right)$ are involved (Ospina et al., 1996). Although high yield is achieved by this route, the chemical synthesis has been criticized for its environment impact. The enzymatic synthesis of ampicillin using penicillin $\mathrm{G}$ acylase (PGA) can be carried out at room temperature $\left(25^{\circ} \mathrm{C}\right)$, aqueous medium and $\mathrm{pH}$ close to the neutrality that allow it being classified as a "green chemistry process".

However, at the moment, substrate yield is one of the main obstacles for this route reaching an industrial implementation. In the enzymatic route, the antibiotic, an intermediary product, is almost completely hydrolyzed at thermodynamically equilibrium. The yield is given by the balance of three reactions, all of them catalyzed by the same enzyme: antibiotic synthesis; acyl-donor hydrolysis (e.g. phenylglycine methyl ester, PGME); and the hydrolysis of the recently synthesized antibiotic.

The kinetics of the enzymatic synthesis of ampicillin is complex and highly non-linear (Gonçalves et al., 2002). Its mechanism involves activation/inhibition of substrates and products, formation of undesired products and an important dependency on $\mathrm{pH}$ and temperature.

Optimization methods are important tools in order to achieve high yields and make the industrial implementation possible. The main objective of this work was to apply optimal control techniques (algorithms), using models from literature to predict optimal feed rates of reactants (PGME, phenylglycine methyl ester and 6-APA, 6aminepenicillanic acid) on a fed-batch reactor.

\footnotetext{
${ }^{*}$ Author for correspondence
} 
Performance criteria (to be maximized) included PGME yield, 6-APA conversion and antibiotic (AMP, ampicillin) productivity (see equations 17, 18 and 19). The range of substrate and product concentrations in study comprised regions above solubility limits. The main reason for this is that the ampicillin precipitation protects itself from enzymatic attack and avoids its hydrolysis.

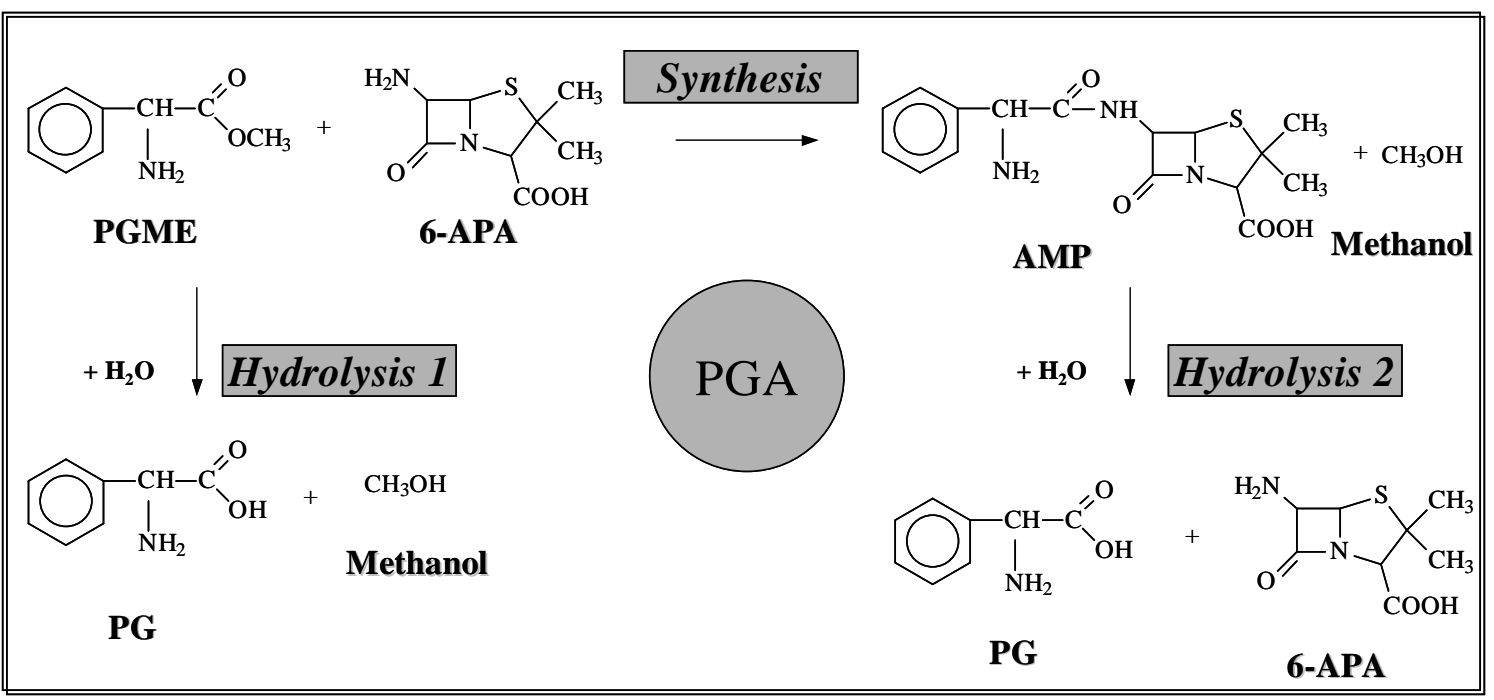

Figure 1 - Main reactions of enzymatic synthesis of ampicillin: PGME, phenylglycine methyl ester; 6-APA: 6-aminopenicillanic acid; AMP, ampicillin; PG, phenylglycine.

\section{Optimal control}

In batch (or semi-batch) process operations, the process variables undergo significant changes during the duration of the batch. There is no steady state and thus no constant set points around which the key variables can be regulated. Hence, the major objective in batch operations is not to keep the system at some optimal constant set points, but rather to optimize an objective function that expresses the system performance (Srivasan et al. 2003).

Optimal control algorithms pursue strategies that minimize (or maximize) performance criteria, expressed by a performance functional (Ramirez, 1994). In other words, they are algorithms that indicate the necessary conditions that will determine an optimal control policy, $u(t)$, leading the system

$$
\underline{\dot{x}}=\underline{f}(\underline{x}, \underline{u}, t), \underline{x}\left(t_{0}\right)=\underline{x}_{0}
$$

following a trajectory, $x(t)$, in which the functional

$$
J(\underline{u})=h\left(\underline{x}\left(t_{f}\right), t_{f}\right)+\int_{t_{0}}^{t_{f}} F(\underline{x}, \underline{u}, t) d t
$$

will be maximized or minimized. $J$ is a performance parameter; $\underline{x}$ is the $n$-dimensional vector of state variables, $\underline{u}$ is the $m$-dimensional vector of control. From the variational calculus, the problem of optimal control without inequality constraints leads to the following equations which have to be solved (Ramirez, 1994):

Equation of Euler-Lagrange

$\underline{\dot{\lambda}}=-\frac{\partial H}{\partial \underline{x}}$

where $\underline{\lambda}$ is the $n$-dimensional vector of adjoint variables (dynamic Lagrange multipliers)

Equation of equality constraints

$\underline{\dot{x}}=\underline{f}(\underline{x}, \underline{u}, t), \underline{x}\left(t_{0}\right)=\underline{x}_{0}$

Transversality condition

$\left[\frac{\partial h\left(t_{f}\right)}{\partial \underline{x}}-\underline{\lambda}\left(t_{f}\right)\right]^{T} \delta \underline{x}_{f}+\left(H\left(t_{f}\right)+\frac{\partial h\left(t_{f}\right)}{\partial t}\right) \delta t_{f}=0$

where $H$ is the Hamiltonian defined as: 
$H=F(\underline{x}, \underline{u}, t)+\underline{\lambda}^{T} \cdot \underline{f}(\underline{x}, \underline{u}, t)$

Optimal control

$\frac{\partial H}{\partial \underline{u}}=\underline{0}$

\section{Kinetic models}

Ferreira et al.(2000) presented a semi-empirical kinetic model to the enzymatic synthesis of ampicillin. The reaction rates proposed by the authors are:

Formation of Acyl-enzyme complex (or rate of ester consuming)

$v_{A B}=\frac{k_{c a t 1} C_{A B} C_{E 0}}{K_{m 1}\left(1+\frac{C_{A N}}{k_{A E}}\right)+C_{A B}}$

\section{Ampicillin synthesis}

$v_{S}=\frac{k_{c a t 1} C_{A B} C_{E 0}}{K_{m 1}\left(1+\frac{C_{A N}}{k_{A E}}\right)+C_{A B}} T_{\max } X$

where

$$
X=\frac{C_{N H}}{K_{E N}+C_{N H}}
$$

\section{Ampicillin hydrolysis}

$$
v_{H 2}=\frac{k_{c a t 2} C_{A N} C_{E 0}}{K_{m 2}\left(1+\frac{C_{A B}}{k_{E A}}\right)+C_{A N}}
$$

where $C_{A N}$ is the ampicillin concentration, $C_{N H}$, the 6-APA concentration and $C_{E O}$, the enzymatic activity. The kinetic parameters has been fitted by Ferreira et al., 2000, at pH 6.5 and temperature at $25^{\circ} \mathrm{C}$. Thus, the reaction rates to each component are:

Reaction rate of PGME (noted by $R_{A B}$ )

$R_{A B}=-v_{A B}$

Reaction rate of Ampicillin $\left(R_{A N}\right)$

$R_{A N}=v_{S}-v_{H 2}$
Reaction rate of 6-APA $\left(R_{N H}\right)$

$R_{N H}=-R_{A N}$

Reaction rate of $P G\left(R_{A O H}\right)$

$R_{A O H}=-R_{A B}-R_{A N}$

\section{Problem formulation}

The optimization of enzymatic synthesis of ampicillin is based mainly in finding a process where 6-APA conversion $(X)$, PGME yields $(Y)$ and antibiotic productivity $(P)$ are maximized. It has been verified (Youshko et al., 2001; Giordano et al., 2003) to the ampicillin synthesis that an integrated fedbatch reactor, in which products crystallization occurs, could have a better performance than a simple batch reactor. In this case, finding an optimal feed trajectory of substrates (6-APA and PGME) becomes necessary. The performance criterion (or functional) used in this work was:

$$
\begin{aligned}
J(\underline{u})= & h\left(\underline{x}\left(t_{f}\right), t_{f}\right)=\left[c_{1} Y^{2}+c_{2} P^{2}+\right. \\
& \left.+c_{3} X^{2}+c_{4} C_{N H}^{2}\right]_{t f}
\end{aligned}
$$

where

$$
\begin{aligned}
& Y=\frac{C_{A N}}{C_{A N}+C_{A O H}} \\
& P=\frac{C_{A N}}{t_{f}} \\
& X=\frac{C_{A N}}{C_{A N}+C_{N H}}
\end{aligned}
$$

where the indexes $A N, N H, A B$ and $A O H$ refer to ampicillin, 6-APA, PGME and PG respectively. The cost constants $c_{i}$ confer weights to each performance variable. As 6-APA is the most expensive and unstable reactant, it has been also added a weight to it (see equation 16, where $c_{4}<0$ and $c_{1}, c_{2}, c_{3}>0$ ) in order to decrease its concentration at the end of the batch.

The mass balance in the fed-batch reactor is:

$$
\frac{d \underline{C}}{d t}=\underline{R}\left(\underline{C}^{s}\right)+\underline{Q}, \underline{C}(0)=\underline{C}_{0}
$$


where $\underline{C}$ is the concentration vector (state vector) and $Q$ is the vector of the feed (control vector). As none of the products are fed, $Q_{A O H}(t)=0, Q_{A N}(t)=0$. $\underline{R}$ is the vector of reaction rates. It was assumed in this work that the volume increasing due the feed of substrates could be neglected. The reason for that assumption is that reactants are fed as solids. Also, the reaction occurs in aqueous-precipitated medium, however the kinetic rates depend on the concentration in solution only, $\underline{C}^{S}$. In this case it was assumed that crystallization occurs instantaneously as soon as the solubility limit, $\underline{C}^{*}$, is achieved. That is:

$$
C_{\mathrm{i}}^{\mathrm{s}}=\left\{\begin{array}{l}
C_{\mathrm{i}} \text { if } C_{\mathrm{i}}<C_{\mathrm{i}}^{*} \\
C_{\mathrm{i}}^{*} \text { if } C_{\mathrm{i}} \geq C_{\mathrm{i}}^{*}
\end{array}\right.
$$

from equations 16, 20 and 21, the necessary conditions to optimality for this problem can be derived:

Equation of Euler-Lagrange (4 equations)

$$
\dot{\lambda}_{i}=-\left[\underline{\lambda}^{T} \frac{\partial \underline{R}\left(\underline{C}^{s}\right)}{\partial C_{i}^{s}}\right] \frac{\partial C_{i}^{s}}{\partial C_{i}}
$$

where

$$
\frac{\partial C_{i}^{s}}{\partial C_{i}}=\left\{\begin{array}{lll}
1 & \text { if } & C_{\mathrm{i}}<C_{\mathrm{i}}^{*} \\
0 & \text { if } & C_{\mathrm{i}} \geq C_{\mathrm{i}}^{*}
\end{array}\right.
$$

Equation 20 represents the four constraints equations. In this work the final time, $t_{f}$, was fixed and therefore, $\delta t_{f}=0$. Hence, the transversality condition yields a boundary condition (at the final time) to the adjoint variables.

$$
\underline{\lambda}\left(t_{f}\right)=\frac{\partial h\left(t_{f}\right)}{\partial \underline{x}}
$$

\section{METHODS}

\section{Algorithm to solve the optimal control problem}

For the determination of the optimal control, equations 20 and 22 must be solved concomitantly from initial conditions, $\underline{C}_{0}$, and final conditions (boundary conditions) of the adjoint variables, equation 24. Partial derivatives of equation 20 were obtained analytically. The procedure adopted was as follows:

1) Choose an initial guess for the reactant feed, $Q_{A B}{ }^{0}(t)$ and $Q_{N H}{ }^{0}(t)$.

2) Integrate the state equations, equation 20 , from initial conditions, $\underline{C}_{0}$ to the final time

3) Integrate the equations of adjoint variables, equation 22 , from its values at the final time, equation 24 , to initial time, $t_{0}$.

4) Update the values of $Q(t)$ using steepest ascendent method.

$$
Q_{i}^{k+1}=Q_{i}^{k}+\eta \frac{\partial H}{\partial Q_{i}^{k}}=Q_{i}^{k}+\eta \lambda^{k}
$$

5) Repeat steps 2-4 until convergence is achieved, that is, $J^{k+1} \approx J^{k}$

Ordinary differential equations were solved using Runge-Kutta $\left(4^{\text {th }}-5^{\text {th }}\right.$ orders $)$ method implemented in FORTRAN. Optimization has been made for the enzymatic synthesis of ampicillin at $25^{\circ} \mathrm{C}$ and $\mathrm{pH}$ at 6.5. Solubility of the components was taken from literature (Vieira, 2003), and their values are: $C^{*}{ }_{A B}=1.2 \mathrm{M} ; C^{*}{ }_{N H}=0.3 \mathrm{M} ; C^{*}{ }_{A M P}=0.050 \mathrm{M}$; $C^{*}{ }_{A O H}=0.015 \mathrm{M}$. The value of the cost constants adopted were: $c_{1}=c_{2}=c_{3}=1$, and $c_{4}=-0.1$.

In order to reduce time consuming and to enhance precision to the final results of the optimization algorithm, parameter $\eta$ began at 0.09 and varied as follows:

- if $J^{k+1}>J^{k}, \eta$ increases $10 \%$ within superior limit of $\eta_{\max }=2.5$.

- if $J^{k+1}<J^{k}, \eta$ decreases $10 \%$ within inferior limit of $\eta_{\min }=1,0 \times 10^{-4}$.

\section{RESULTS AND DISCUSSION}

Figs. 2, 4 and 6 depict the results obtained for the optimal feed of reactants for three different final times $\left(t_{f}\right): 200,300$ and 500 minutes. Semi-batch simulations of the synthesis using trajectories obtained by optimization are shown in Figs. 3, 5 and 7. 


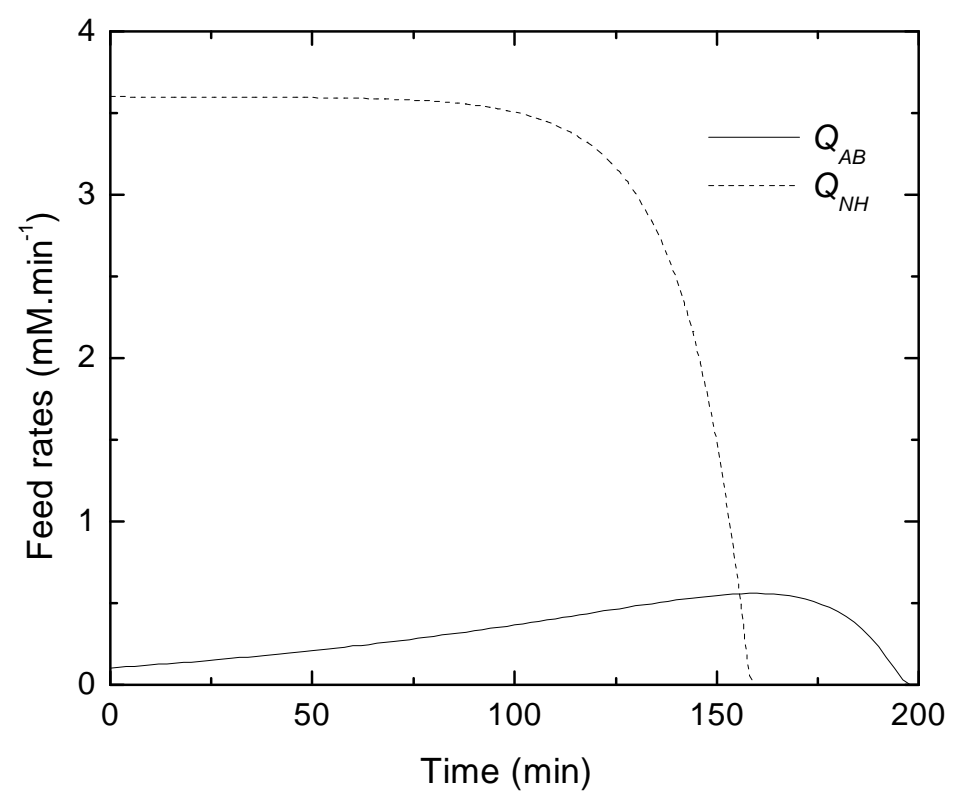

Figure 2 - Optimal trajectories of feed rates obtained to the synthesis of ampicillin. Final time: $t_{f}=200 \mathrm{~min}$.

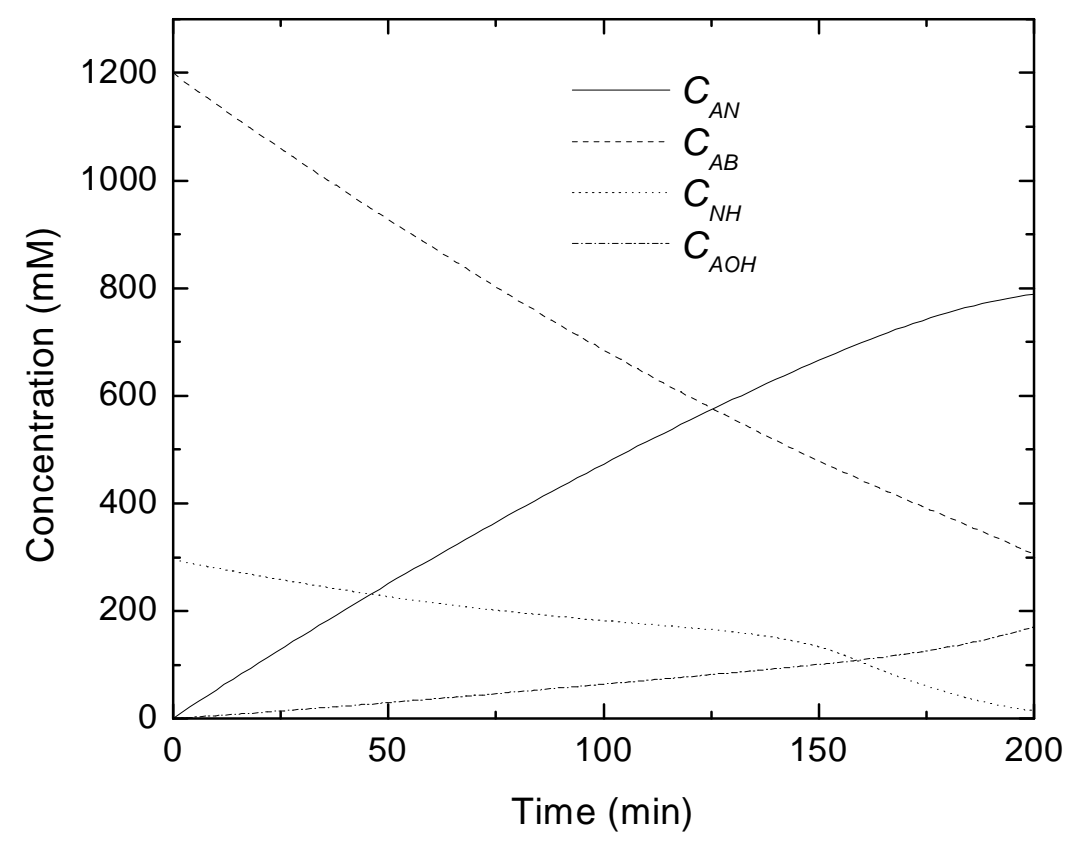

Figure 3 - Simulation of synthesis using optimal feed rates obtained. $t_{f}=200 \mathrm{~min}$. 


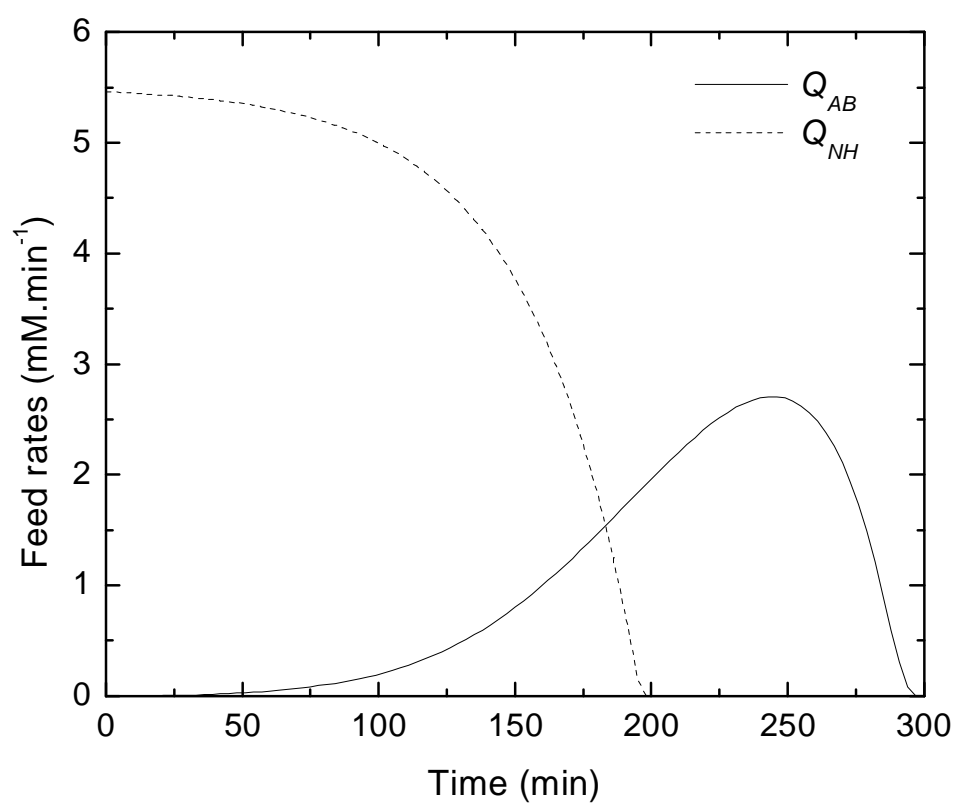

Figure 4 - Optimal trajectories of feed rates obtained to the synthesis of ampicillin. Final time: $t_{f}=300 \mathrm{~min}$.

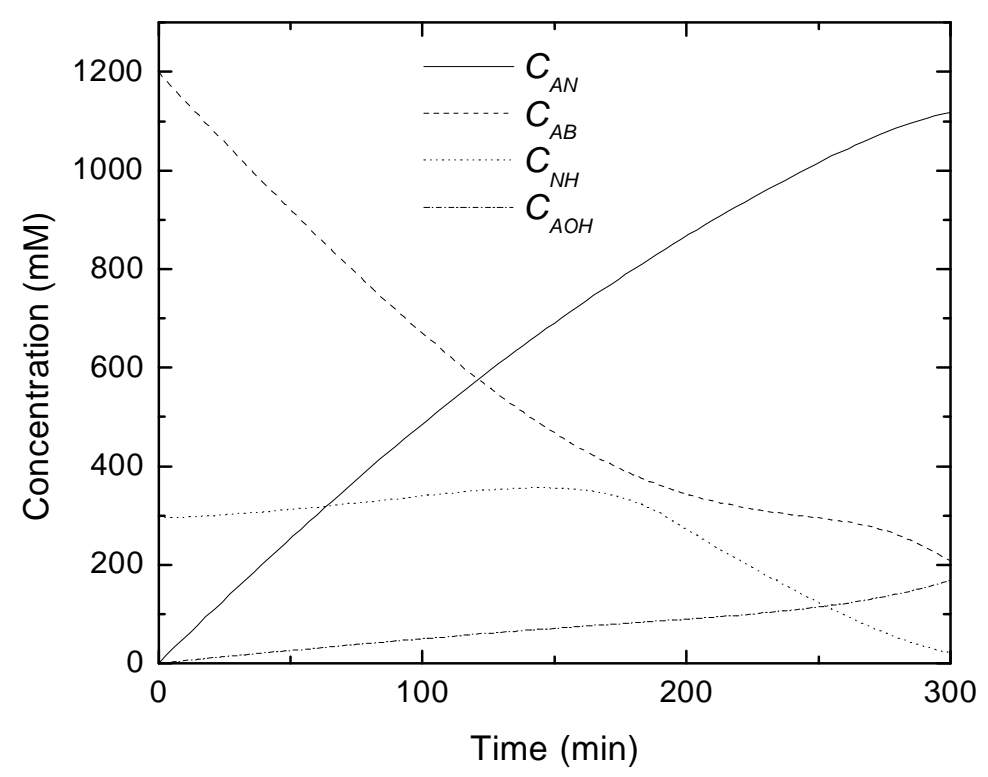

Figure 5 - Simulation of synthesis using optimal feed rates obtained. $t_{f}=300 \mathrm{~min}$. 


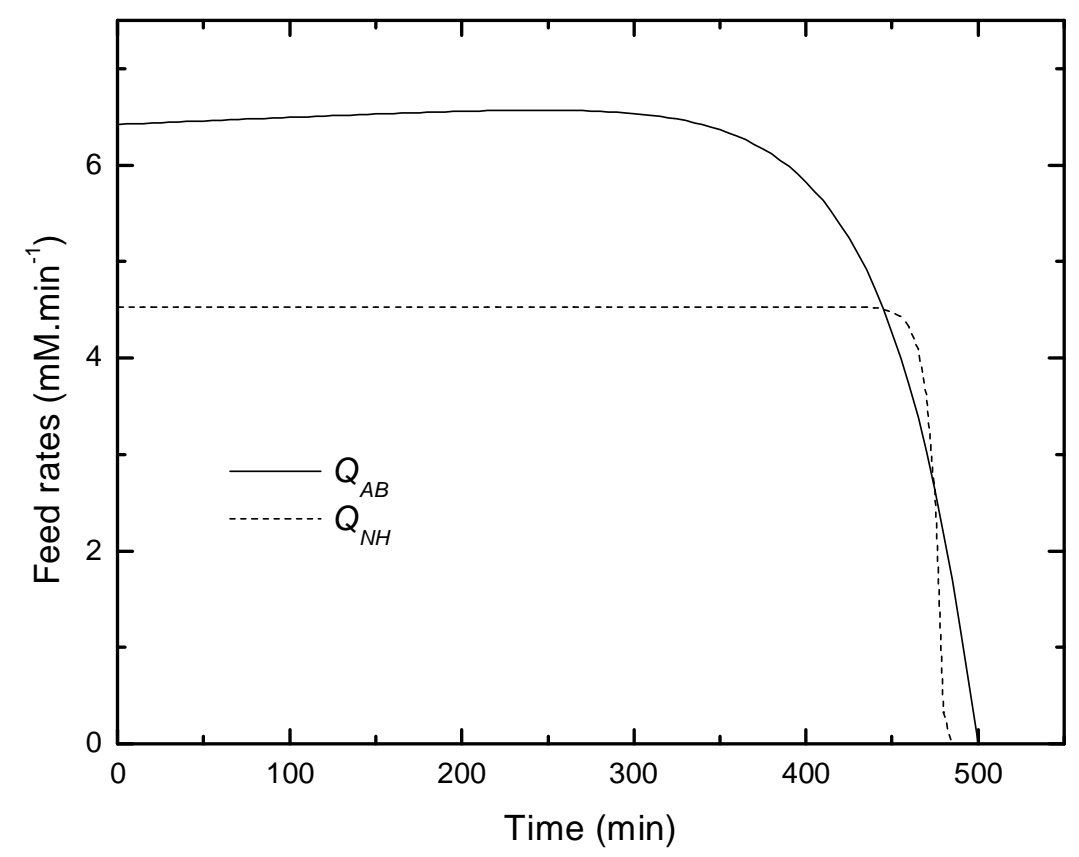

Figure 6 - Optimal trajectories of feed rates obtained to the synthesis of ampicillin. Final time: $t_{f}=500 \mathrm{~min}$.

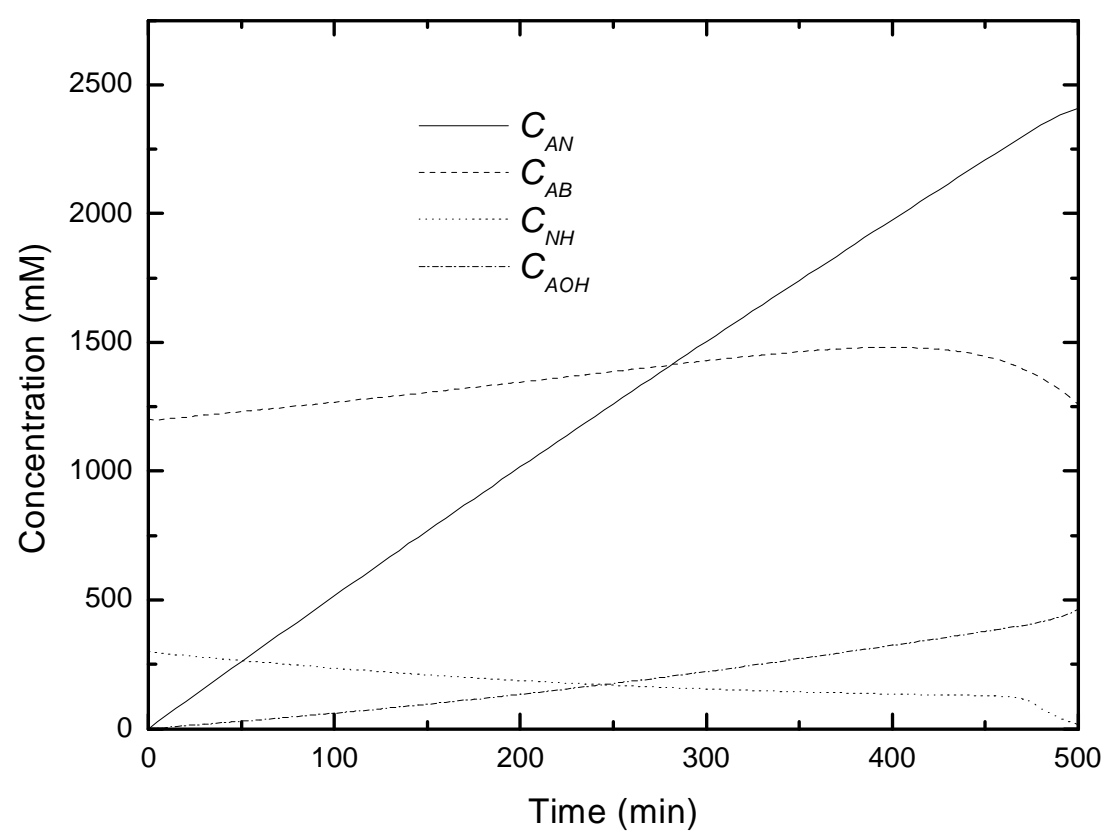

Figure 7 - Simulation of synthesis using optimal feed rates obtained. $t_{f}=500 \mathrm{~min}$. 
High 6-APA feed rates were obtained at the beginning of the synthesis as optimal trajectories for final times at 200 and 300 minutes. These trajectories were expected because it was necessary to keep the concentration of 6-APA at higher value while PGME was consumed. The optimal PGME feed rates obtained became higher at the end of the synthesis. The reason for increase was the cost added at the functional $J$ for the final concentration of 6-APA which decreased faster when the concentration of ester was enhanced. Results obtained for 500 minutes as final time in contrast, seemed to differ from the others. Feed rates for PGME were most of the time higher than for 6-APA. In this case, an increase of the yield of PGME and productivity seemed to overcome the final 6-APA conversion (see Fig. 9) at least for the weights used in this optimization. However, using this strategy, the high concentration of PGME at the end of the synthesis (Fig. 7) could cause difficulty in the subsequent step, the product separation. It was not the case with the others two strategies (Figs. 3 and 5) where concentration of the PGME was lower than its solubility.

Although an optimal final time was also dependent on others factors (unloading time, mixture viscosity, reaction volume increasing) and the final concentration of the components changed considerably from different final times (Fig. 8), it could be noticed, for any of the simulations, that the conversion and yield were between 86 and 92\% (Fig. 9), which were promising results for the enzymatic synthesis of ampicillin. Moreover, high concentrations of ampicillin $(1.0$ to $2.5 \mathrm{M})$ were reached in the simulations that would facilitate the separation step (Fig. 8).

In order to obtain more realistic results, it would be necessary to have a functional in which real process costs would be incorporated and, therefore, the real process cost would be minimized.

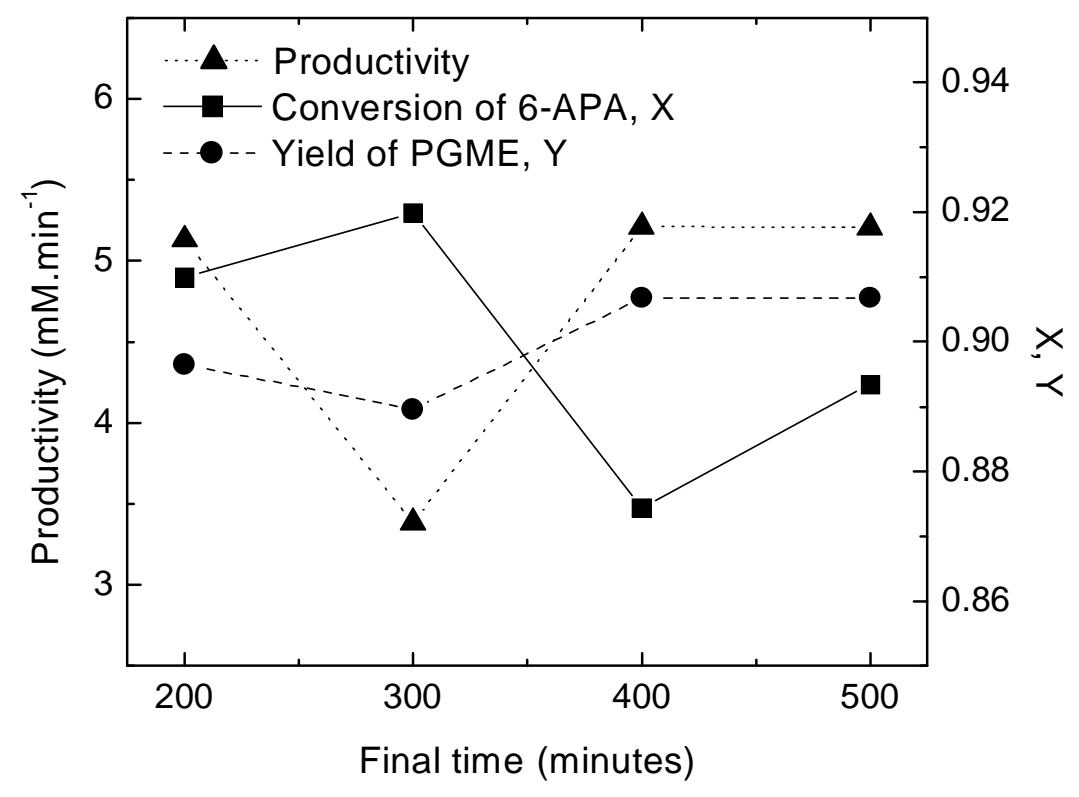

Figure 8 - Concentration of reactants and products at the end of the semi-batch for different final times. 


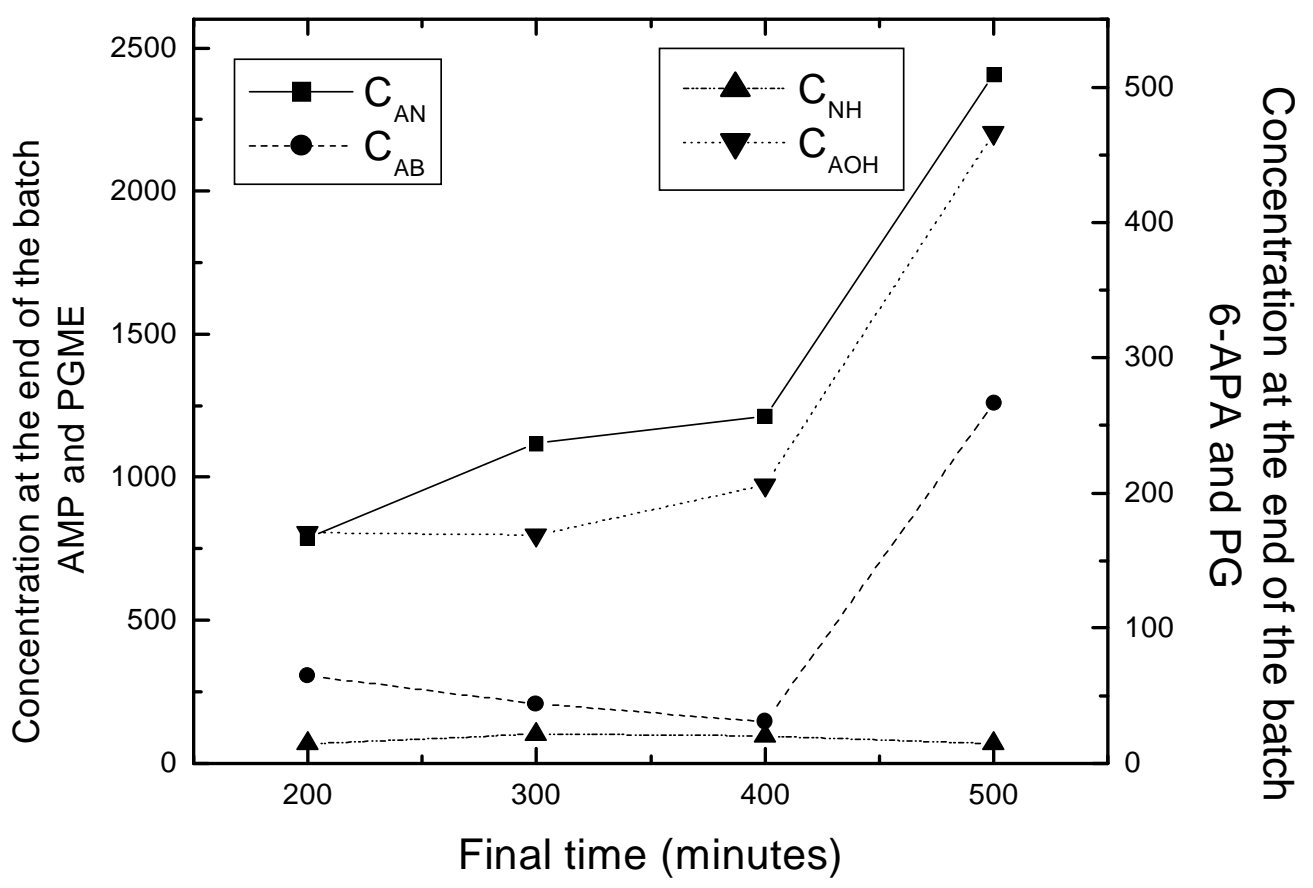

Figure 9 - Productivity, conversion of 6-APA and yield of PGME at the end of the semi-batch for different final times.

\section{CONCLUSION}

Optimal control techniques, using kinetic models from the literature, were applied with success, predicting optimal trajectories for the feed rates of substrates in a semi-batch reactor of enzymatic synthesis of ampicillin. 6-APA conversion, PGME yield and ampicillin productivity were maximized (for a fixed enzymatic concentration). A penalty to the final concentration of 6-APA was also added to the proposed functional in order to minimize 6-APA wastes (the most expensive and unstable substrate). Studied region also included concentrations above solubility limits of substrates and products with the purpose of protecting the antibiotic of enzymatic attack, i.e., avoiding its hydrolysis. The results showed that an integrated (with products/substrates crystallization) semi-batch reactor could enhance yields and conversions. It would also provide high concentration of antibiotic in the reactor that would make its separation easier. This work presented an available method to attack the problem in a rational manner. Certainly, a functional that takes into account the real costs of reactants, products and operation should be defined for an industrial case. Also, the influence of the final time of the reaction must be further well studied.

\section{ACKNOWLEDGEMENTS}

The authors thank the Brazilian research-funding agency FAPESP (State of Sao Paulo).

\section{RESUMO}

A síntese enzimática de ampicilina oferece menor impacto ambiental em relação ao processo utilizado atualmente pela indústria farmacêutica. Mas seu rendimento e produtividade devem ser melhorados para tornar essa rota competitiva. Alguns estudos empíricos para otimizar a rota enzimática de síntese de antibióticos $\beta$-lactâmicos vêm sendo realizados. Entretanto, a utilização sistemática de métodos matemáticos de otimização nesse processo não é encontrada na literatura. 
Neste trabalho, utilizaram-se técnicas de controle ótimo para otimizar a alimentação de reagentes na síntese enzimática de ampicilina em reator operando em batelada alimentada. Resultados simulados mostram que, em reator integrado (com precipitação dos produtos) operado em batelada alimentada, conversões de 6-APA e rendimento de EMFG de $88 \%$ a $92 \%$ são factíveis, assim como produtividades entre 3,5 e 5,5 mM.min ${ }^{-1}$.

\section{REFERENCES}

Ferreira, A. L. O.; Gonçalves, L. R. B.; Giordano, R. L. C. and Giordano, R. C. (2000), A simplified kinetic model for the side reactions occurring during the enzymatic synthesis of ampicillin. Braz. J. Chem. Eng., 17, 835-839.

Giordano, R. C.; Ferreira, A. L. O.; Ribeiro, M. P. A.; Vieira, M. F. and Giordano L. C. (2003), Nova concepção de biocatalisador enzimático insolúvel para aplicação em biorreatores integrados. Paper presented at the Encontro brasileiro sobre tecnologia na indústria química (I Enbteq), São Paulo.

Gonçalves, L. R. B.;Sousa, R.; Fernandez-Lafuente, R.; Guisan, J. M.; Giordano, R. L. C. and Giordano, R. C. (2002), Enzymatic synthesis of amoxicillin: avoiding limitations of the mechanistic approach for reaction kinetics. Biotechnology And Bioengineering, 80, 622-631.

Ospina, S.; Barzana, E.; Ramírez, O. T. and LópezMunguía, A. (1996), Strategies in the design of an enzymatic process for the synthesis of ampicillin: A Whole cell e. coli recombinant penicillin amidase biocatalyst. Prog. Biotechnol., 11, 464-471.

Ramirez, W. F. (1994), Process control and identification. San Diego : Academic Press Inc.
Srinivasan, B.; Palanki, S. and Bonvin, D. (2003), Dynamic optimization of batch processes. I. Characterization of the nominal solution. Computers and Chemical Eng., 27, 1-26.

Vieira, M. F. (2003), Separação de ampicilina obtida por síntese enzimática cineticamente controlada. PhD Thesis, Universidade Federal de São Carlos, São Carlos, Brazil.

Youshko, M. I.; Langen, L. M.; Vroom, E.; Rantwijk, F.; Sheldon, R. A. and Svedas, V. K. (2001), Highly efficient synthesis of ampicillin in "aqueous solutionprecipitate" systems: repetitive addition of substrates in a semicontinuous process. Biotechnology And Bioengineering, 73, 426-430.

Received: September 29, 2004; Revised: February 25, 2005; Accepted: March 25, 2005. 